(c) American Dairy Science Association, 2004.

\title{
Evaluation of Serotypes of Staphylococcus aureus Strains Used in the Production of a Bovine Mastitis Bacterin
}

\author{
J. Ma, ${ }^{1}$ J. Cocchiaro, ${ }^{2}$ and J. C. Lee ${ }^{2}$ \\ ${ }^{1}$ Biological Research and Development, Boehringer Ingelheim Vetmedica, Inc., \\ St. Joseph, MO 64506 \\ ${ }^{2}$ Channing Laboratory, Department of Medicine, Brigham and Women's Hospital, \\ Harvard Medical School, Boston, MA 02130
}

\begin{abstract}
The five Staphylococcus aureus strains used in the manufacture of a commercially available bacterin were examined for capsular and surface polysaccharide serotypes. Double immunodiffusion assays of antigenic extracts of test and reference strains with monospecific typing sera to capsular serotypes $1,2,5$, and 8 and to surface polysaccharide serotype 336 were performed to detect the specific reactivities and antigenic relationships of test samples. Antigenic extracts of two $S$. aureus strains reacted with antibodies to serotype 8 , but not with antibodies to serotype 5 , by producing specific precipitin lines. A third strain reacted with monospecific antibodies to serotype 5 and not with the antibodies to serotype 8 . The extracts of two other strains failed to exhibit any detectable reaction with antiserum to serotypes $1,2,5$, or 8 . Antibodies to serotype 336 , however, precipitated an identical, specific 336 antigen from the antigenic extracts of these two nontypeable strains. Thus, $S$. aureus bacterin includes one serotype 5, two serotype 8 , and two serotype 336 strains, the three predominant serotypes responsible for bovine mastitis.
\end{abstract}

(Key words: serotype, Staphylococcus aureus, bacterin, capsule)

Abbreviation key: NT = nontypeable.

\section{INTRODUCTION}

Staphylococcus aureus, a common etiologic agent of contagious bovine mastitis, is an encapsulated, grampositive bacterium. The capsular polysaccharide is antiphagocytic and is one of many virulence factors produced by this pathogen (Peterson et al., 1978; Karakawa et al., 1982; Thakker et al., 1998). The S. aureus capsular polysaccharides are serotype-specific, and an-

Received March 20, 2003.

Accepted May 14, 2003.

Corresponding author: J. Ma; e-mail: jma@bi-vetmedica.com. tibodies to the capsule facilitate opsonophagocytic killing of $S$. aureus by leukocytes to enhance host immunity to staphylococcal infection (Karakawa et al., 1988; Lee et al., 1997; Thakker et al., 1998). Polysaccharides purified from $S$. aureus serotypes $1,2,5$, and 8 have been characterized biochemically (Lee, 2001a). A new serotype, called 336, has been reported (Guidry et al., 1998), but the chemical composition of this antigen has not been characterized.

Bovine mastitis is characterized by inflamed mammary glands, abnormal milk, and reduced milk yield. Severe cases of bovine mastitis may manifest with symptoms such as fever, depression, anorexia, and weight loss. It is the most significant cause of economic loss to the dairy industry, with estimated annual losses greater than $\$ 1.8$ billion in the United States (Clements, 1998). Most cases of mastitis emerge during lactation and may affect up to $50 \%$ of dairy cattle (Clements, 1998). Cows with staphylococcal infection are reservoirs for new disease. Antimicrobial therapy is not considered effective, particularly for established $S$. aureus infections of deep mammary-gland tissue. Therefore, immunoprophylaxis is a desired measure for the prevention and control of bovine mastitis.

The $S$. aureus bacterin, LYSIGIN (Boehringer Ingelheim Vetmedica, Inc., St. Joseph, MO), is a commercially available vaccine against staphylococcal bovine mastitis. Both experimental vaccination/challenge trials and field efficacy trials have demonstrated that the bacterin significantly reduced experimental IMI, SCC in acute mastitis, and clinical cases of mastitis (Williams et al., 1966, 1975). A clinical investigation that extended across three lactations showed that the bacterin was capable of reducing SCC in udders infected with $S$. aureus (Pankey et al., 1985). The use of the bacterin also enhanced the spontaneous cure of $S$. aureus IMI induced by experimental challenge (Pankey et al., 1985). Furthermore, a field trial using dairy heifers has confirmed the efficacy of the bacterin (Nickerson et al., 1999), since vaccinated heifers had significantly fewer new S. aureus IMI and chronic IMI due to Staphylococcus spp. during pregnancy and at freshening under field conditions. 
The $S$. aureus bacterin is composed of five $S$. aureus strains, one each of phage types I through IV and a nontypeable (NT) strain. Research during the last decades, however, has not substantiated the significance of phage typing clinically or immunologically. Instead, serotyping of $S$. aureus based on the capsular polysaccharide has emerged and now plays an important role in vaccine research and development (Karakawa et al., 1982; Lee, 2001b). The present study demonstrates that the five $S$. aureus strains used in the manufacture of the $S$. aureus bacterin encompass one serotype 5, two serotype 8 , and two serotype 336 isolates, the three predominant serotypes causing bovine mastitis. Our investigation also shows that the serotype 336 antigen is not only present on nonencapsulated staphylococci but can also be detected on some serotypes 5 or 8 strains.

\section{MATERIALS AND METHODS}

\section{Bacterial Strains}

Staphylococcus aureus strains A, B, C, D, and E (designated names) used for the production of $S$. aureus bacterin are all of bovine origin. The five bacterin strains were provided in duplicate to one of the authors (J.C.L.), and each sample was coded and tested in a blinded fashion. Staphylococcus aureus strains Wood 46 (ATCC 10832, a capsule NT strain), acapsular mutants JL243 (derived from a parent serotype 5 strain), and JL252 (derived from a parent serotype 8 strain) have been described elsewhere (Baddour et al., 1992; Thakker et al, 1998). The WSU 18 (serotype 8), AA119 (serotype 8), and Myco 6 (serotype 5) are bovine isolates that were included in a previous serotyping study (Tollersrud et al., 2000). Fourteen encapsulated S. aureus isolates recovered from individual cases of bovine mastitis were tested for the presence of 336 antigen. Three of the isolates were provided by investigators at the University of California at Davis (Tulare), three were from Washington State University, and two each were from Louisiana State University and Pennsylvania State University. Four isolates were provided from the University of Vermont. Nine of the 14 isolates were positive for CP8 and five were positive for CP5. Reference $S$. aureus strains and their serotypes are shown in Table 1.

\section{Serotyping Antisera to Capsular Polysaccharides}

Polyclonal antisera to serotypes 1 (SA1 mucoid), 2 (Smith diffuse), 5 (Reynolds), and 8 (PS80) were produced in rabbits to heat- or formalin-killed suspensions of $S$. aureus strains. To remove antibodies to noncapsular cell wall determinants, antisera were adsorbed overnight at $4^{\circ} \mathrm{C}$ on a rotator with $S$. aureus Wood 46 and
Table 1. Reference Staphylococcus aureus strains and their serotypes.

\begin{tabular}{lll}
\hline S. aureus strain & Serotype & Reference \\
\hline M & 1 & Karakawa and Vann, 1982 \\
SA1 mucoid & 1 & Lee et al., 1987 \\
Smith diffuse & 2 & Karakawa and Vann, 1982 \\
Reynolds & 5 & Karakawa and Vann, 1982 \\
Newman & 5 & Sau et al., 1997 \\
PS80 & 8 & Tzianabos et al., 2001 \\
RN450 & $\mathrm{NT}^{1}$ & Novick, 1963 \\
55804 & 336 & ATCC \\
\hline
\end{tabular}

${ }^{1} \mathrm{NT}=$ capsule nontypeable (not reactive with antibodies to serotype 5 or 8 S. aureus ).

trypsinized cells of acapsular mutants JL243 and JL252. Sera were clarified by centrifugation and passage through a $0.45-\mu \mathrm{m}$ filter. The efficiency of adsorption was verified by immunodiffusion assays. Each antiserum reacted only with control capsular extracts prepared from $S$. aureus cells of homologous, but not heterologous, capsular serotypes. Monospecific capsular antisera also failed to react with extracts made from NT S. aureus RN450 or acapsular mutant strains.

\section{Serotyping Antisera to Serotype 336}

Polyclonal antiserum to $S$. aureus serotype 336 was prepared by a modification of the procedure previously described (Karakawa et al., 1985). Briefly, two rabbits were immunized with formalin-killed $S$. aureus 55804 cells. When the titer of serum antibody reached $\geq 1280$ by microagglutination assay with strain 55804 cells, the rabbits were exsanguinated. Serum was adsorbed with acapsular mutant JL252 as described above. The specificity of anti-serotype 336 was confirmed with 336 antigen purified from the reference strain ATCC 55804.

\section{Antigenic Extracts}

Bacterial extracts from test and reference strains of $S$. aureus were prepared as previously described (Tollersrud et al., 2000). Briefly, S. aureus isolates were grown for $24 \mathrm{~h}$ at $37^{\circ} \mathrm{C}$ on either tryptic soy agar (Becton Dickinson, Sparks, MD) or Columbia agar (Becton Dickinson) supplemented with $2 \% \mathrm{NaCl}$. The colonies from one plate $(9 \mathrm{~cm}$ in diameter) were harvested in $1 \mathrm{ml}$ of $10 \mathrm{~m} M$ PBS $(0.15 M \mathrm{NaCl}, \mathrm{pH}$ 7.2). The cell suspensions were autoclaved for $1 \mathrm{~h}$ at $121^{\circ} \mathrm{C}, 15 \mathrm{psi}$. The bacteria were pelleted by centrifugation, and the supernatants containing the cell extracts were passed through 0.45 $\mu \mathrm{m}$ filters and stored at $-20^{\circ} \mathrm{C}$.

\section{Serotyping}

Currently accepted serotyping methods to determine the specific reactivity of test isolates with antisera to 
MA ET AL.

Table 2. Specific reactivity of Staphylococcus aureus cell extracts with antisera by immunodiffusion. ${ }^{1}$

\begin{tabular}{|c|c|c|c|c|c|c|c|}
\hline \multicolumn{2}{|c|}{$\begin{array}{l}\text { Cell extracts } \\
\text { of } S \text {. aureus }\end{array}$} & \multicolumn{5}{|c|}{$\begin{array}{l}\text { Reactivity of bacterial extracts } \\
\text { with antiserum to antigen type }\end{array}$} & \multirow[b]{2}{*}{ Serotype } \\
\hline $\begin{array}{l}\text { Reference } \\
\text { strains }\end{array}$ & $\begin{array}{l}\text { Test sample } \\
\text { No. (strain) }\end{array}$ & 1 & 2 & 5 & 8 & 336 & \\
\hline \multirow{2}{*}{\multicolumn{2}{|c|}{$\begin{array}{l}\text { M } \\
\text { Smith }\end{array}$}} & + & - & - & - & ND & 1 \\
\hline & & & & & & & \\
\hline \multicolumn{2}{|l|}{ diffuse } & - & + & - & - & ND & 2 \\
\hline \multicolumn{2}{|l|}{ Newman } & - & - & + & - & - & 5 \\
\hline \multicolumn{2}{|l|}{ PS80 } & - & - & - & + & - & 8 \\
\hline \multirow{2}{*}{\multicolumn{2}{|c|}{$\begin{array}{l}\text { RN450 } \\
55804\end{array}$}} & - & - & - & - & + & $336(\mathrm{NT})$ \\
\hline & & - & - & - & - & + & $336(\mathrm{NT})$ \\
\hline \multicolumn{2}{|r|}{289 (A) } & ND & ND & + & - & + & $5\left(336^{*}\right)$ \\
\hline & 369 (A) & ND & ND & + & - & + & $5(336)$ \\
\hline & 292 (B) & - & - & - & - & + & $336(\mathrm{NT})$ \\
\hline & 397 (B) & - & - & - & - & + & $336(\mathrm{NT})$ \\
\hline & $298(\mathrm{C})$ & - & - & - & - & + & $336(\mathrm{NT})$ \\
\hline & $384(\mathrm{C})$ & - & - & - & - & + & $336(\mathrm{NT})$ \\
\hline & 276 (D) & ND & ND & - & + & - & 8 \\
\hline & 400 (D) & ND & ND & - & + & - & 8 \\
\hline & $254(\mathrm{E})$ & ND & ND & - & + & - & 8 \\
\hline & $375(\mathrm{E})$ & ND & ND & - & + & - & 8 \\
\hline
\end{tabular}

\footnotetext{
$1_{-}=$Specific reaction negative, $+=$specific reaction positive, $\mathrm{ND}=$ not determined, $\mathrm{NT}=$ nontypeable by
} capsular serotyping, $*$ = also antigen 336 positive.

serotypes 5 and 8 include slide agglutination, immunoprecipitation, colony immunoblot, and ELISA inhibition (Karakawa et al., 1985; Guidry et al., 1998; Tollersrud et al., 2000). The NT isolates were tested for 336 serotype by immunoprecipitation (Guidry et al., 1998). We used immunoprecipitation (double immunodiffusion) for serotyping of bacterin strains and clinical isolates as previously described (Karakawa et al., 1985). Briefly, a $1 \%$ agarose gel was prepared on a glass slide, and wells were punched in a circular fashion around a central hole. Antiserum was added to the central well and bacterial extracts (including known serotype antigen extract controls) were applied to the outer wells. Immunodiffusion was conducted in a moist chamber at room temperature. After 24 to $48 \mathrm{~h}$, the precipitin lines were examined directly or by staining with Coomassie brilliant blue.

\section{RESULTS AND DISCUSSION}

Capsular polysaccharide serotyping of $S$. aureus was first reported in 1982 (Karakawa et al., 1982). The results of epidemiologic surveys show that more than $98 \%$ of isolates from bovine milk samples or clinical isolates from cases of mastitis in Europe, the United States, and Argentina belong to serotypes 5 or 8 or are capsule NT (Poutrel et al, 1988; Guidry et al., 1998; Sordelli et al., 2000; Tollersrud et al., 2000). The latter group has been reported to carry the 336 antigen, although there is no evidence that this is a capsular antigen. Nonetheless, surface polysaccharide antigens of $S$. aureus are serotype-specific immunogens, and antibodies to these antigens have been shown to be opsonic (Karakawa et al., 1988; Thakker et al., 1998; O'Brien et al., 2000). Antibody-mediated phagocytosis is considered to be the most important defense mechanism against bacterial infection in the bovine mammary gland (Paape et al., 1981). A vaccine effective in the field must confer protection against these major pathogenic serotypes.

The serotyping results of the duplicate isolates of the five bacterin strains were identical (Table 2). The extracts from strain A and control strain Newman produced precipitin lines of identity with monospecific antibodies to serotype 5 , but they did not react with antibodies to serotype 8 , demonstrating that strain A was serotype 5. Immunoprecipitation of extracts from separate duplicate samples of strains $\mathrm{D}$ and $\mathrm{E}$ and control strain PS80 formed precipitin lines of identity with the monospecific antibodies to serotype 8 but failed to react with antibodies to serotype 5 . Thus, strains D and E produce serotype 8 capsule. Extracts made from $S$. aureus strains B and C failed to react with antibodies to capsule types $1,2,5$, or 8 (Table 2). However, extracts from both strains reacted with antibodies to serotype 336 and demonstrated precipitin lines of identity with ATCC 55804 (Figure 1). This result demonstrated that the NT strains B and C produced antigen 336.

We performed additional experiments to determine whether serotype 5 and 8 strains of $S$. aureus might also produce antigen 336 . Fourteen bovine isolates from the United States were tested for 336 antigen by immunodiffusion. One of five serotype $5 \mathrm{~S}$. aureus isolates and two of nine serotype 8 isolates reacted with 336 antiserum. The extracts from two serotype 5 (including 


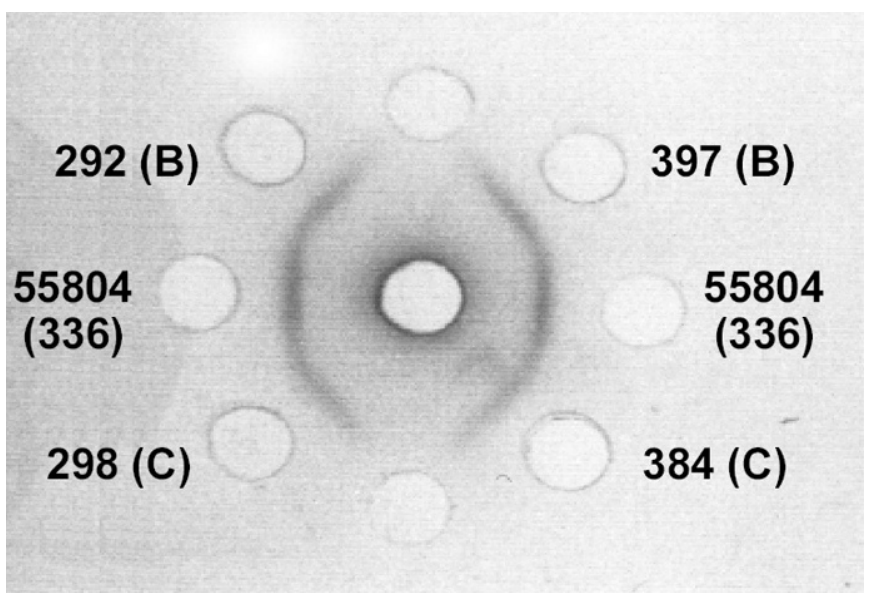

Figure 1. Immunodiffusion analysis of antigenic extracts of nontypeable strains of Staphylococcus aureus with antiserum to serotype 336 . Thirty microliters of monospecific antiserum to serotype 336 adsorbed with JL252 was added to the center well. Twenty microliters of antigenic extracts of test strains or reference strain 55804 (serotype 336; diluted 1:10) was added to the outer wells. Precipitin lines of identity between the test strains and reference strain 336 were detected after staining with Coomassie brilliant blue.

bacterin strain A) and two serotype 8 S. aureus bovine isolates produced precipitin lines of identity with strain 336 when reacted with 336 antiserum (Figure 2). The extent of the association of serotype 336 antigen with strains of serotypes 5 and 8 is unknown. It is plausible that antigen 336 is a cell wall-associated polysaccharide that is made in greater abundance or more easily detected on strains lacking a capsule. It seems that the

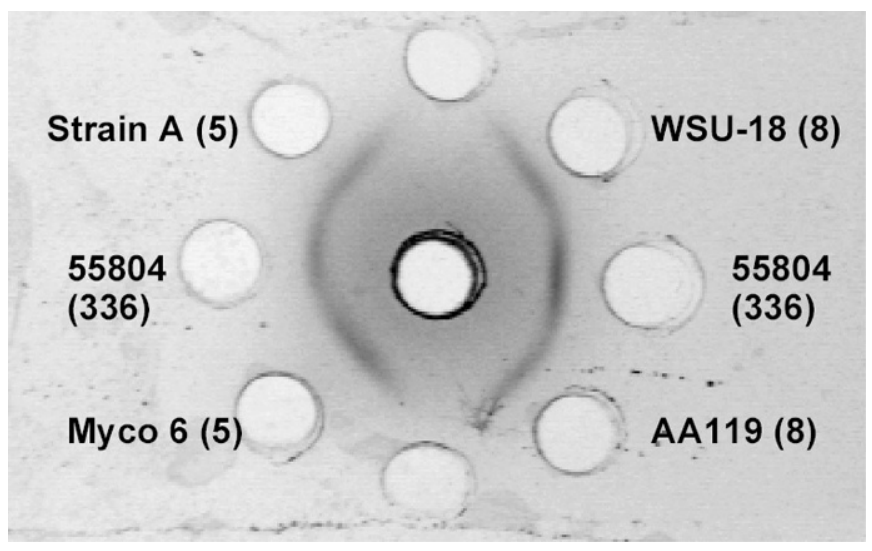

Figure 2. Immunodiffusion analysis of antigenic extracts with serotype 336 antiserum. Fifteen microliters of monospecific antiserum to serotype 336 adsorbed with strain JL252 was added to the center well. Thirty microliters of antigenic extracts of test samples (strain A and other bovine isolates positive for capsule type 5 or 8) was added to the outer wells. The extract from reference strain 336 was diluted 1:10, and $10 \mu \mathrm{l}$ of the diluted extract was added to the well. Precipitin lines were visualized after staining with Coomassie brilliant blue. current $S$. aureus serotyping schemes are based on both capsular and cellular polysaccharides, representing two different serotyping schemes. Thus, the classification of serotype 336, its chemical structure, and its significance merit further investigation. Antigen 336 has been described as a $\mathrm{N}$-acetylglucosamine-containing polymer. Whether it resembles $S$. aureus cell wall teichoic acid (known to be substituted with $\mathrm{N}$-acetylglucosamine) has not yet been adequately addressed.

Our results indicate that the five $S$. aureus strains used in the manufacture of the $S$. aureus bacterin comprise one serotype 5 , two serotype 8 , and two serotype 336 isolates, the three predominant serotypes of bovine clinical isolates in Europe and the United States $(\mathrm{Gu}-$ idry et al., 1998; Tollersrud et al., 2000). The bacterin is formulated with whole-cell lysates of the five strains and an adjuvant. Thus, this formulation provides coverage for all three major serotypes of $S$. aureus pathogens causing bovine mastitis. An experimental efficacy trial showed protection against all three serotypes (Williams et al., 1975). In the trial, 54 quarters of vaccinated Holstein heifers and 20 quarters of nonvaccinated control heifers were challenged by the intramammary route with the same five $S$. aureus strains in a pooled mixture. During 3 mo of clinical observations following challenge, only $6 \%$ of quarters in the vaccinated group developed chronic staphylococcal mastitis, whereas $100 \%$ of quarters of the control cows exhibited chronic mastitis. The efficacy of the bacterin in reducing new or chronic IMI and in promoting spontaneous cure of clinical mastitis has also been shown under field conditions by either experimental or natural exposure in heifers or older lactating cows from different locations (Williams et al., 1966; Pankey et al., 1985; Nickerson et al., 1999). This investigation better characterizes the serotype composition of the current vaccine formulation, further clarifies the protective efficacy of the bacterin by eliciting antibodies directed against each of the most prevalent serotypes of mastitis-causing strains of $S$. aureus and provides guidance for the development of an improved $S$. aureus bacterin for better control and prevention of bovine mastitis.

\section{REFERENCES}

Baddour, L. M., C. Lowrance, A. Albus, J. H. Lowrance, S. K. Anderson, and J. C. Lee. 1992. Staphylococcus aureus microcapsule expression attenuates bacterial virulence in a rat model of experimental endocarditis. J. Infect. Dis. 165:749-753.

Clements, M. 1998. Mastitis: Pathogens and global incidence. Pages $7-13$ in Bovine Mastitis: Products and Markets. Animal Pharm Reports. Surrey, UK.

Guidry, A. A., A. Fattom, A. Patel, C. O'Brien, S. Shepherd, and J. Lohuis. 1998. Serotyping scheme for Staphylococcus aureus isolated from cows with mastitis. Am. J. Vet. Res. 59:1537-1539.

Karakawa, W. W., J. M. Fournier, W. F. Vann, R. Arbeit, R. S. Schneerson, and J. B. Robbins. 1985. Method for the serological 
typing of the capsular polysaccharides of Staphylococcus aureus. J. Clin. Microbiol. 22:445-447.

Karakawa, W. W., A. Sutton, R. Schneerson, A. Karpas, and W. F. Vann. 1988. Capsular antibodies induce type-specific phagocytosis of capsulated Staphylococcus aureus by human polymorphonuclear leukocytes. Infect. Immun. 56:1090-1095.

Karakawa, W. W., and W. F. Vann. 1982. Capsular polysaccharides of Staphylococcus aureus. Semin. Infect. Dis. 4:285-293.

Lee, C. Y. 2001a. Capsule production. Pages 35-45 in Staphylococcus aureus infection and disease. A. L. Honeyman, H. Friedman, and M. Endinelli, eds. Kluwer Academic/Plenum Publishers, New York, NY.

Lee, J. C. 2001b. Capsule and vaccine development. Pages 49-63 in Staphylococcus aureus infection and disease. A. L. Honeyman, H. Friedman, and M. Endinelli, eds. Kluwer Academic/Plenum Publishers, New York, NY.

Lee, J. C., F. Michon, N. E. Perez, C. A. Hopkins, and G. B. Pier. 1987. Chemical characterization and immunogenicity of capsular polysaccharide isolated from mucoid Staphylococcus aureus . Infect. Immun. 55:2191-2197.

Lee, J. C., J.-S. Park, S. E. Shepherd, V. Carey, and A. Fattom. 1997. Protective efficacy of antibodies to the Staphylococcus aureus type 5 capsular polysaccharide in a modified model of endocarditis in rats. Infect. Immun. 65:4146-4151.

Nickerson, S. C., W. E. Owens, G. M. Tomita, and P. W. Widel. 1999. Vaccinating dairy heifers with a $S$. aureus bacterin reduces mastitis at calving. Large Anim. Practice 20:16-28.

Novick, R. P. 1963. Properties of a cryptic high-frequency transducing phage in Staphylococcus aureus. Virology 33:155-166.

O'Brien, C. N., A. J. Guidry, A. Fattom, S. Shepherd, L. W. Douglass, and D.C. Westhoff. 2000. Production of antibodies to Staphylococcus aureus serotypes 5, 8, and 336 using poly(DL-lactide-co-glycolide) microspheres. J. Dairy Sci. 83:1758-1766.

Paape, M. J., W. P. Wergin, and A. J. Guidry. 1981. Phagocytic defense of the ruminant mammary gland. Adv. Exp. Med. Biol. 137:555-578.

Pankey, J. W., N. T. Boddie, L. J. Watts, and S. C. Nickerson. 1985. Evaluation of protein $\mathrm{A}$ and a commercial bacterin as vaccines against Staphylococcus aureus mastitis by experimental challenge. J. Dairy Sci. 68:726-731.

Peterson, P. K., B. J. Wilkinson, Y. Kim, D. Schmeling, and P. G. Quie. 1978. Influence of encapsulation on staphylococcal opsonization and phagocytosis by human polymorphonuclear leukocytes. Infect. Immun. 19:943-949.

Poutrel, B., A. Boutonnier, L. Sutra, and J. M. Fournier. 1988. Prevalence of capsular polysaccharide types 5 and 8 among Staphylococcus aureus isolates from cow, goat, and ewe milk. J. Clin. Microbiol. 26:38-40.

Sau, S., N. Bhasin, E. R. Wann, J. C. Lee, T. J. Foster, and C. Y. Lee. 1997. The Staphylococcus aureus allelic genetic loci for serotype 5 and 8 capsule expression contain type-specific genes flanked by common genes. Microbiology 143:2395-2405.

Sordelli, D. O., F. R. Buzzola, M. I. Gomez, L. Steele-Moore, D. Berg, E. Gentilini, M. Catalano, A. J. Reitz, T. Tollersrud, G. Denamiel, P. Jeric, and J. C. Lee. 2000. Capsule expression by bovine isolates of Staphylococcus aureus from Argentina: Genetic and epidemiologic analyses. J. Clin. Microbiol. 38:846-850.

Thakker, M., J. S. Park, V. Carey, and J. C. Lee. 1998. Staphylococcus aureus serotype 5 capsular polysaccharide is anti-phagocytic and enhances bacterial virulence in a murine bacteremia model. Infect. Immun. 66:5183-5189.

Tollersrud, T., K. Kenny, A. J. Reitz, and J. C. Lee. 2000. Genetic and serologic evaluation of capsule production by bovine mammary isolates of Staphylococcus aureus and other Staphylococcus spp. from Europe and the United States. J. Clin. Microbiol. 38:2998-3003.

Tzianabos, A. O., J. Y. Wang, and J. C. Lee. 2001. Structural rationale for the modulation of abscess formation by Staphylococcus aureus capsular polysaccharides. Proc. Natl. Acad. Sci. USA 98:93659370.

Williams, J. M., H. J. Mayerhofer, and R. W. Brown. 1966. Clinical evaluation of a Staphylococcus aureus bacterin (polyvalent somatic antigen). Vet. Med./Small Anim. Clin. 61:789-794.

Williams, J. M., G. R. Shipley, G. L. Smith, and D. L. Gerber. 1975. A clinical evaluation of Staphylococcus aureus bacterin in the control of staphylococcal mastitis in cows. Vet. Med./Small Anim. Clin. 70:587-594. 